\title{
FIRMEZA DE MAMÃO TRATADO COM 1-MCP EM DIFERENTES TEMPOS DE EXPOSIÇÃO
}

\author{
Firmness of papaya treated with 1-MCP in different exposition times
}

\author{
Simone Abreu Asmar', Celeste Maria Patto de Abreu², Rafaella Araújo Zambaldi Lima ${ }^{3}$, \\ Angelita Duarte Corrêa ${ }^{2}$, Custódio Donizete dos Santos ${ }^{2}$
}

\begin{abstract}
RESUMO
O mamão é um fruto climatérico cujas transformações resultantes do amadurecimento ocorrem rapidamente após a colheita do fruto fisiologicamente maduro, desencadeadas pela produção do etileno e aumento da taxa respiratória. Isso o caracteriza como um fruto bastante perecível após a colheita. Dada essa alta perecibilidade, o controle do amadurecimento é fundamental para o aumento na vida útil pós-colheita, visando ao mercado interno e à exportação de frutas. O composto 1-metilciclopropeno (1-MCP) vem sendo usado com a finalidade de controlar o amadurecimento de frutos, flores e hortaliças. Neste trabalho foi avaliada a ação do tratamento com 1-MCP, em diferentes tempos de exposição, em mamões armazenados em condições ambiente. Os frutos foram colhidos no estádio 1 de maturação e foram submetidos ao 1-MCP, na concentração de $270 \mathrm{~nL} / \mathrm{L}$, por um período de $0,12,18$ e 24 horas e, em seguida, armazenados em condição ambiente (T $\left.22 \pm 2^{\circ} \mathrm{C} / \mathrm{UR} 77 \% \pm 2 \%\right)$, por 8 dias. Os frutos tratados com 1-MCP apresentaram maior firmeza, menores teores de pectina solúvel e menor atividade de enzima PME mostrando que o 1-MCP foi eficiente em retardar o amaciamento dos frutos no período estudado.
\end{abstract}

Termos para indexação: Carica papaya, pós-colheita, amadurecimento.

\begin{abstract}
The papaya is a climateric fruit whose transformations resulting from ripening occur shortly after the picking of the physiologically ripe fruit, triggered by the production of ethylene and increased breathing rate. That makes it a quite perishable fruit after harvest. Given that perishability, ripening control is fundamental to increase post-harvest shelf life, both for internal consumption and exports. The compound 1-methylcyclopropene (1-MCP) has been used with the purpose of controlling the ripening of fruits, flowers and vegetables. In this work, the effect of the treatment with 1-MCP on papayas stored under room conditions was evaluated in different exposure periods. The fruits were picked at stage 1 of maturation and were submitted to $1-\mathrm{MCP}$, at the concentration of $270 \mathrm{~nL} / \mathrm{L}$, for a period of $0,12,18$ and 24 hours, and then stored under room conditions ( $\mathrm{T} 22 \pm 2^{\circ} \mathrm{C} / \mathrm{RH} 77 \% \pm 2 \%$ ) for 8 days. The 1-MCP-treated fruits showed increased firmness, lower contents of soluble pectin and less activity of PME enzyme, showing that 1-MCP was effective in delaying the softening of the fruits over the studied period.
\end{abstract}

Index terms: Carica papaya, post-harvest, ripening.

(Recebido em 8 de setembro de 2008 e aprovado em 26 de novembro de 2009)

\section{INTRODUÇÃO}

O mamão é um fruto climatérico, cujas transformações resultantes do amadurecimento ocorrem rapidamente no fruto fisiologicamente maduro, desencadeadas pela produção do etileno e o aumento da taxa respiratória, o que o torna um fruto bastante perecível em pós-colheita. Em razão dessa alta perecibilidade, o controle do amadurecimento é fundamental para o aumento na vida útil após a colheita, visando ao mercado interno e à exportação de frutas. O etileno está envolvido na aceleração do amadurecimento e senescência de frutos climatéricos. Em determinado estádio de maturação, o etileno liga-se ao seu receptor na célula, um complexo protéico-enzimático, e desencadeia uma série de eventos que culminam com o amadurecimento e senescência dos frutos (Lelièvre et al., 1997). Tem sido verificado que a inibição da ligação do etileno ao seu receptor pode reduzir a produção e ação do mesmo e, com isso, retardar o amadurecimento e a senescência desses frutos. O 1metilciclopropeno (1-MCP) é um composto volátil que tem demonstrado ser um potente inibidor da ação do etileno, retardando o amadurecimento (Serek et al., 1995). Ele se liga fortemente ao sítio do etileno, evitando a ligação e a ação do mesmo. De acordo com a Portaria $n^{\circ} 354$, de 11 de agosto de 2006, da Agência Nacional de Vigilância

\footnotetext{
${ }^{1}$ Universidade Federal de Lavras/UFLA - Cx. P. 3037 - 37200-000 - Lavras, MG - siasmar@yahoo.com.br

'Universidade Federal de Lavras/UFLA - Departamento de Química/DQI - Lavras, MG

3Universidade Federal de Lavras/UFLA - Lavras, MG
} 
Sanitária-ANVISA (2006), o 1-MCP foi liberado para ser utilizado no Brasil em diferentes plantas ornamentais e frutos, dentre os quais se inclui o mamão. Neste trabalho, objetivou-se avaliar o efeito do 1-MCP em diferentes tempos de exposição $(0,12,18$ e 24 horas) sobre a manutenção da firmeza em mamões 'Sunrise Solo' destinados ao consumo in natura, armazenados em condições ambientais.

\section{MATERIAL E MÉTODOS}

Os frutos do mamoeiro (Carica papaya L.) do grupo Solo, cultivar Sunrise Solo, produzidos no município de Linhares, ES, foram colhidos em setembro de 2007, no estádio 1 de maturação (a cor amarela não cobre mais de $15 \%$ da superfície da casca). Os frutos foram transportados para o CEASA em Belo Horizonte e, posteriormente, foram trazidos para o Laboratório de Bioquímica do Departamento de Química da Universidade Federal de Lavras. Dos 250 frutos colhidos, foram selecionados 180 em função do tamanho, cor, ausência de injúrias mecânicas e fisiológicas. Logo depois, foram imersos em uma solução de hipoclorito de sódio a 2,5\%, por 1 minuto, para desinfecção. Em seguida, foram colocados sobre papel toalha, para secar, à temperatura ambiente. Após essa etapa, foram separados, ao acaso, em 4 lotes de 45 frutos cada, sendo: 1ํo lote: controle (0 hora de exposição ao 1-MCP); $2^{\circ}$ lote: os frutos foram submetidos à exposição de 1-MCP pelo período de 12 horas; 3 o lote: os frutos foram submetidos à exposição de 1-MCP pelo período de 18 horas e 4o lote: os frutos foram submetidos à exposição de 1-MCP, pelo período de 24 horas. A aplicação constou da colocação dos frutos em câmara hermética (caixa de isopor de 100L) e exposição ao 1-MCP, na concentração de 270nL/L, para o 2º, o $3^{\circ}$ e o $4^{\circ}$ lotes. Ao final de cada tempo, os frutos foram retirados das câmaras, codificados, pesados e armazenados à temperatura ambiente $\left(22 \pm 2^{\circ} \mathrm{C}\right.$ e $77 \pm 2 \%$ UR), por 8 dias. As análises foram iniciadas logo após a aplicação do 1MCP (24 horas depois que correspondeu ao dia zero) e, a cada 2 dias, até o fim do período de armazenamento, o mesmo ocorreu para os frutos controle. Os frutos foram descascados e picados. Uma parte foi congelada em nitrogênio líquido e armazenada em sacos de polietileno hermeticamente fechados, devidamente identificados e acondicionados a $-18^{\circ} \mathrm{C}$, para a análise de atividade enzimática. A outra parte foi triturada em liquidificador, até a obtenção de uma massa homogênea, sendo também acondicionada em sacos de polietileno hermeticamente fechados, devidamente identificados e armazenados, a $18^{\circ} \mathrm{C}$, para a realização das outras análises.
Foram realizadas as seguintes análises:

- Firmeza: foi medida nos frutos inteiros, utilizando-se um texturômetro modelo TA.TX2i, equipado com sonda de aço inoxidável de $6 \mathrm{~mm}$ de diâmetro $(\mathrm{P} / 6 \mathrm{~N})$, que mediu a força de penetração com velocidade de descida de $2 \mathrm{~mm} / \mathrm{s}$ e com distância máxima de introdução de $3 \mathrm{~mm}$.

- Pectinas total e solúvel: foram extraídas segundo a técnica descrita por McCready \& McComb (1952) e determinadas colorimetricamente, segundo Bitter \& Muir (1962). Os resultados foram expressos em g de ácido galacturônico/100g de polpa.

- Atividade de pectinametilesterase: determinada segundo Jen \& Robinson (1984).

$\mathrm{O}$ experimento foi conduzido em delineamento inteiramente casualizado (DIC), em esquema fatorial (4x5) x 3, sendo 4 tratamentos (controle, exposição ao 1metilciclopropeno, ou 1-MCP, por 12 horas, por 18 horas e por 24 horas), 5 tempos de análise, correspondentes aos dias 0, 2, 4, 6 e 8, com 3 repetições, em que cada parcela era composta por 3 frutos. Os resultados foram submetidos à análise de variância, por meio do programa Sisvar. Para a descrição das variáveis em função dos períodos de armazenamento, foram feitas análises de regressão e os modelos polinomiais foram selecionados observando-se a significância do teste F, para cada modelo e seus respectivos coeficientes de determinação.

\section{RESULTADOS E DISCUSSÃO}

Houve efeito significativo $(\mathrm{P}<0,05)$ para a interação entre os fatores estudados (tratamentos $\mathrm{x}$ dias de armazenamento), para todos os parâmetros. Verificou-se que, ao longo do período de armazenamento, houve um decréscimo na firmeza dos mamões (Figura 1), como consequência do avanço do processo natural de amaciamento e senescência dos frutos para todos os tratamentos. No entanto, os frutos do tratamento controle tornaram-se mais amolecidos quando comparados aos frutos tratados com 1-MCP. Os frutos expostos ao período de 24 horas ao 1-MCP apresentavam maior firmeza até, aproximadamente, o 8 dia de armazenamento, mostrando que este tempo de exposição foi melhor que os outros.

Jacomino et al. (2007) realizaram estudo com mamões 'Golden, no qual avaliaram a influência do intervalo entre a colheita e a aplicação do 1-MCP, na concentração de $100 \mathrm{~nL} / \mathrm{L}$, aplicado após 0, 1, 2 e 3 dias da colheita, no estádio 2 de maturação. Os frutos foram armazenados a $11^{\circ} \mathrm{C}$, por um período de seis dias e, posteriormente, colocados à temperatura ambiente até o completo amadurecimento. Os autores verificaram 
redução da firmeza da polpa dos mamões, após a colheita, mesmo sob refrigeração. Os frutos que receberam 1-MCP perderam a firmeza mais lentamente do que os frutos sem 1-MCP. A retenção da firmeza em resposta ao tratamento com 1-MCP também foi verificada por Ergun \& Huber (2004), em mamões ‘Sunrise Solo’ e Hofman et al. (2001).

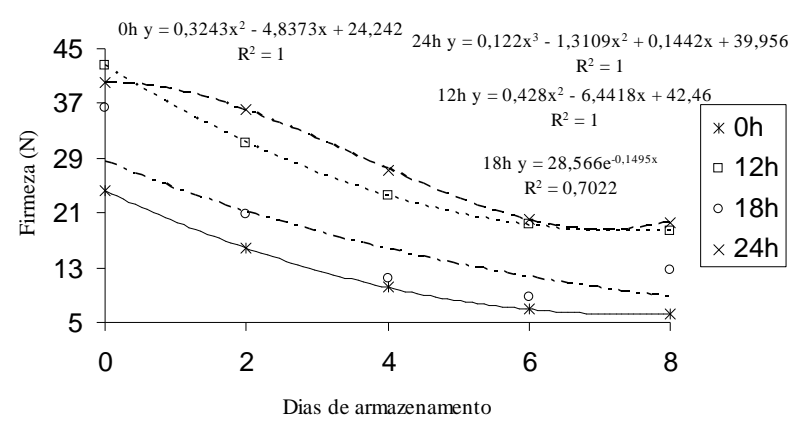

Figura1 - Firmeza em mamões 'Sunrise Solo' submetidos ao tratamento com 1-MCP, em quatro tempos e armazenados, pelo período de oito dias, sob condição ambiente.

Houve decréscimo no teor de pectina total nos frutos de todos os tratamentos (Figura 2). Nos frutos controle, esse teor já se apresentava menor do que os frutos tratados com 1-MCP no dia 0 (24 horas após todos os tratamentos), sugerindo que o 1-MCP pode ter retardado a degradação da pectina total. Observou-se tendência de queda nos teores de pectina total, em todos os tempos de exposição ao 1-MCP durante o amadurecimento, no entanto, o tratamento de 24 horas apresentou queda menos acentuada que nos demais tratamentos.

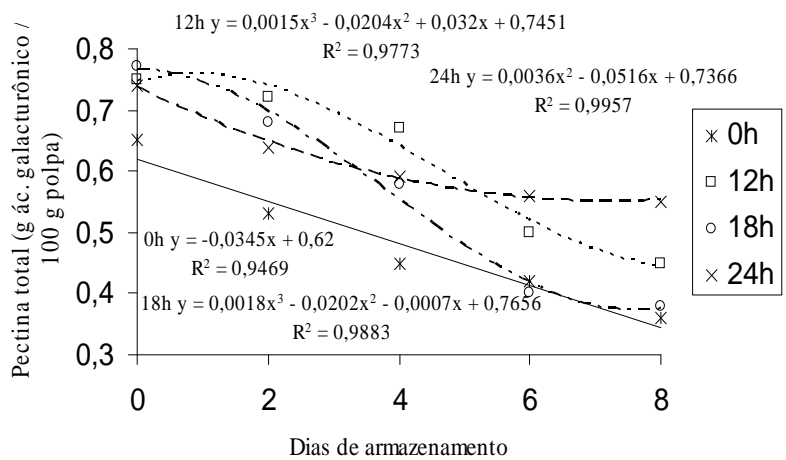

Figura 2 - Teores médios de pectina total em mamões 'Sunrise Solo' submetidos ao tratamento com 1-MCP, em quatro tempos e armazenados, pelo período de oito dias, sob condição ambiente.
Quanto ao teor de pectina solúvel, os frutos controle e os submetidos ao 1-MCP, em todos os tempos de exposição, apresentaram aumento durante todo o período de armazenamento, em função do amadurecimento (Figura 3). Observa-se que, no dia 0 (24 horas após a montagem do experimento), os teores de pectina solúvel nos frutos controle já eram bem superiores, quando comparados aos teores dos frutos tratados com 1-MCP. Estes apresentaram teores mais baixos e solubilização mais lenta o que, possivelmente, contribuiu para que o amaciamento desses frutos fosse menos acentuado, demonstrando que a aplicação de 1-MCP, mesmo nos diferentes tempos de exposição, pode influir, reduzindo ou retardando a atividade das enzimas pécticas.

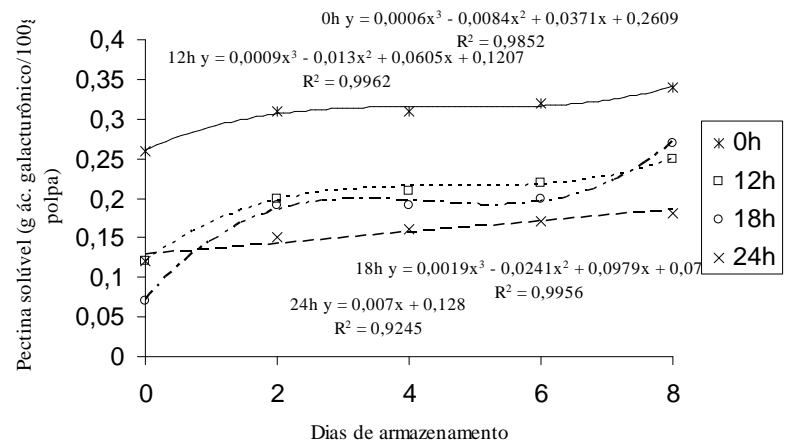

Figura 3 - Teores médios de pectina em mamões 'Sunrise Solo' submetidos ao tratamento com 1-MCP, em quatro tempos e armazenados, pelo período de oito dias, sob condição ambiente.

O incremento no teor de pectina solúvel observado neste trabalho é condizente com os resultados encontrados por Arriola et al. (1975), Draetta et al. (1975) e Lazan et al. (1991), que também verificaram aumento durante o amadurecimento de mamões.

O período de 24 horas, decorrido entre o começo da aplicação do tratamento e o tempo zero, mostrou que, nos frutos tratados com 1-MCP, a atividade da enzima pectinametilesterase (PME) encontrava-se baixa (Figura 4). Isso indica que o 1-MCP interferiu na degradação da pectina pelo controle da atividade da PME, fato que reflete diretamente na firmeza dos frutos. A atividade da PME aumentou tanto para os frutos controle quanto para os frutos tratados com 1-MCP, independente do tempo de exposição em que os frutos foram submetidos, até o 6o dia de armazenamento, quando então, começou a decair. Os frutos tratados por 24 horas apresentaram menor atividade da PME durante todo o período de armazenamento. 


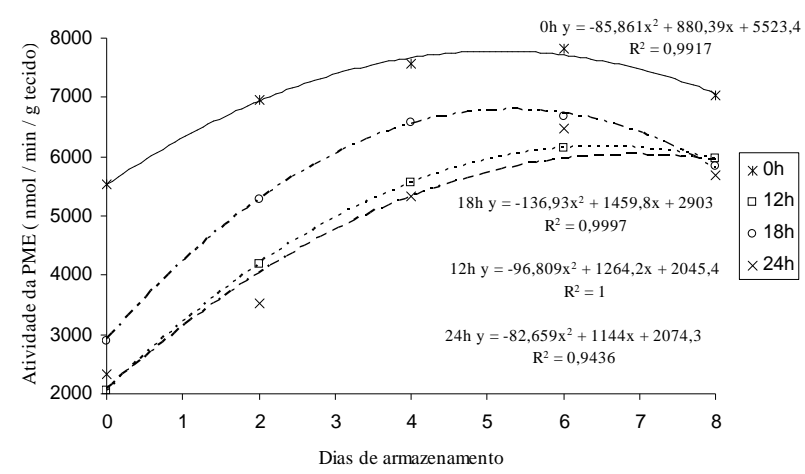

Figura 4 - Atividade de pectinametilestersase em mamões 'Sunrise Solo' submetidos ao tratamento com 1-MCP, em quatro tempos e armazenados, por um período de oito dias, sob condição ambiente.

Bron (2006), avaliando mamões do grupo Solo, cultivar Golden, tratados com 1-MCP na concentração de $100 \mathrm{~nL} / \mathrm{L}$ e $\operatorname{armazenados}$ a $11^{\circ} \mathrm{C}$, por 20 dias e, posteriormente, mantidos a $23^{\circ} \mathrm{C}$, até o completo amadurecimento, definido como a casca completamente amarela, verificou que, durante o armazenamento refrigerado dos frutos não tratados com 1-MCP, houve aumento da atividade da PME. Também constatou que a atividade da PME, durante o armazenamento refrigerado dos frutos tratados com 1-MCP, se manteve constante, sem qualquer aumento. Após a remoção da refrigeração, a atividade também não se alterou até o 7 o dia, quando, então, passou a aumentar, atingindo valor máximo aos 9 dias.

Apesar de se ter detectado atividade da enzima PME, uma das pectinases envolvidas no processo de amaciamento, com consequente aumento nos teores de pectina solúvel, não se pode inferir que somente essa enzima esteja envolvida no processo de degradação. D'Innocenzo \& Lajolo (2001) relatam que a perda de firmeza na polpa de mamão também está relacionada com a atividade das enzimas poligalacturonase e $B$ galactosidase.

\section{CONCLUSÕES}

Nas condições experimentais, pode-se concluir que os frutos tratados com 1-MCP se apresentaram com menor perda de firmeza durante todo o período de armazenamento à temperatura ambiente, quando comparados aos frutos controle e o tempo de exposição ao 1 -MCP por um período de 24 horas foi mais eficiente sobre os parâmetros analisados que os demais tratamentos.

\section{REFERÊNCIAS BIBLIOGRÁFICAS}

AGÊNCIA NACIONAL DE VIGILÂNCIA SANITÁRIA.

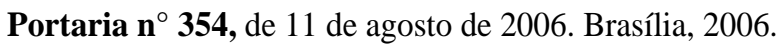
Disponível em: 4 http://www.anvisa.gov.br/base/visadoc/ 'CP/CP $\%$ B $17161-1-0 \% 5 \mathrm{D} . \mathrm{PDF}>$. Acesso em: 16 mar. 2008.

ARRIOLA, M.C. de; MADRID, M.C. de; ROLZ, C. Alguns cambios fisicos y quimicos de la papaya durante su almacenamiento. Proceedings of Tropical Region of the American Society of Horticultural Science, Orlando, v.19, p.97-109, 1975.

BITTER, T.; MUIR, H.M. A modified uronic acid carbazole reaction. Analytical Biochemistry, New York, v.34, n.4, p.330-334, 1962.

BRON, I.U. Amadurecimento do mamão ‘Golden': ponto de colheita, bloqueio da ação do etileno e armazenamento refrigerado. 2006. 66p. Dissertação (Doutorado em Agronomia)-Escola Superior de Agricultura Luiz de Queiroz, Piracicaba, 2006.

D'INNOCENZO, M.; LAJOLO, F.M. Effect of gamma irradiation on textura changes and enzyme activities during ripening of papaya fruit. Journal of Food Biochemistry, Amsterdam, v.25, n.5, p.425-438, 2001.

DRAETTA, I. dos S.; SHIMOKOMAKI, M.; YOKOMIZO, Y.; FUJITA, J.T.; MENEZES, H.C. de; BLEINROTH, E.W. Transformações bioquímicas do mamão (Carica papaya) durante a maturação. Coletânea do Instituto de tecnologia de Alimentos, Campinas, v.6, p.395-408, 1975.

ERGUN, M.; HUBER, D.J. Suppression of ethylene perception extends shelf-life and quality of 'Sunrise Solo' papaya fruit at both pre-ripe and ripe stages of development. European Journal of Horticultural Science, Hannover, v.69, n.5, p.184192, 2004.

HOFMAN, P.J.; JOBIN-DÉCOR, M.; MEIBURG, G.F.; MACNISH, A.J.; JOYCE, D.C. Ripening and quality responses of avocado, custard apple, mango and papaya fruit to 1-methylcyclopropene. Australian Journal Experimental Agriculture, Melbourne, v.41, p.567-572, Jan. 2001. 
JACOMINO, A.P.; TREVISAN, M.J.; ARRUDA, M.C. de; KLUGE, R.A. Influência do intervalo entre a colheita e a aplicação do 1-metilciclopropeno no controle do amadurecimento de mamão. Revista Brasileira de Fruticultura, Jaboticabal, v.29, n.3, 2007.

JEN, J.J.; ROBINSON, M.L.P. Pectolytic enzymes in sweet bell peppers (Capsicum annuиm L.). Journal of Food Science, Chicago, v.49, n.4, p.1085-1087, July/Aug. 1984.

LAZAN, H.; ALI, Z.M.; SIM, W.C. Retardation of ripening and development of water stress in papaya fruit seal-packaged with polyethylene film. Acta

Horticulturae, Amsterdam, n.269, p.345-358, 1991.
LELIÈVRE, J.M.; TICHIT, L.; DAO, P.; FILLION, L.; NAM, Y.W.; PECH, J.C.; LATCHÉ, A. Effects of chilling on the expression of ethylene biosynthetic genes in Passe-Crassane pear (Pyrus communis L.) fruits. Plant Molecular Biology, Dordrecht, v.33, p.847-855, 1997.

McCREADY, P.M.; McCOMB, E.A. Extraction and determination of total pectic material. Analytical Chemistry, Washington, v.24, n.12, p.1586-1588, Dec. 1952.

SEREK, M.; TAMARI, G.; SISLER, E.C. 1Methylcyclopropene, a novel gaseous inhibitor of ethylene action, improves the life of fruit, cut flowers and potted plants. Acta Horticulturae, Amsterdam, v.394, p.337-345, 1995. 